\title{
Study of Abiotic and Biotic Parameters Affecting the Abundance of Mosquito Larvae (Diptera: Culicidae) in the Region of Fez (Morocco)
}

\author{
Touria Filali Mouatassem, ${ }^{1}$ Abdelhakim El Ouali Lalami ${ }^{10},{ }^{1,2}$ Chafika Faraj, ${ }^{3}$ \\ Noureddine Rais, ${ }^{4}$ and Raja Guemmouh ${ }^{1}$ \\ ${ }^{1}$ Laboratory of Biotechnology and Preservation of Natural Resources, Sidi Mohamed Ben Abdellah University, \\ Faculty of Sciences Dhar El Mahraz, Fez 30000, Morocco \\ ${ }^{2}$ Higher Institute of Nursing Professions and Health Techniques of Fez, Regional Health Directorate, El Ghassani Hospital, \\ $\mathrm{Fez}$ 30000, Morocco \\ ${ }^{3}$ Laboratory of Medical Entomology, National Hygiene Institute, Rabat 11400, Morocco \\ ${ }^{4}$ Laboratory of Computer Science, Modelling and Systems, Sidi Mohamed Ben Abdellah University, \\ Faculty of Sciences Dhar Mahraz, Fez 30000, Morocco
}

Correspondence should be addressed to Abdelhakim El Ouali Lalami; eloualilalami@yahoo.fr

Received 25 March 2020; Revised 24 June 2020; Accepted 6 July 2020; Published 27 July 2020

Academic Editor: Joao Pedro Barreiros

Copyright (C) 2020 Touria Filali Mouatassem et al. This is an open access article distributed under the Creative Commons Attribution License, which permits unrestricted use, distribution, and reproduction in any medium, provided the original work is properly cited.

\begin{abstract}
Mosquitoes cause significant human health issues. However, very few studies have attempted to examine the question of how abiotic and biotic factors affect the abundance of Culicidae in the larval habitat. The objective of this study was to analyze the influence of biotic and abiotic factors on the increase of the most common mosquito species in the Fez region (Central Morocco). Larvae mosquitoes were sampled by standard dipping technique in four different types of macrohabitats, between November 2015 and November 2016. Each mosquito specimen was morphologically identified by the Moroccan Culicidae key and the Brunhes key. The analysis was done using $R$ analysis software. We collected a total of 772 mosquito larvae belonging to nine different species, five of which are considered of medical interest. Culex pipiens (Linnaeus, 1758), known as the major vector in the transmission of West Nile virus fever (WNV), was the most common species of all mosquito larvae collected. The results of Poisson regression analysis showed that factors such as the presence of green filamentous algae, vegetation cover, and debris were found to be positively significant in the distribution of the genus Culex. However, there was insufficient evidence to determine the parameters that are capable of estimating the abundance of Anopheles. The findings have also estimated that biotic and abiotic factors can lead to significant variation in the abundance of Culex perexiguus (Theobald, 1903), Culex theileri (Theobald, 1903), and Culex pipiens (Linnaeus, 1758). Identifying the priority parameters governing the proliferation of mosquitoes in the region of Fez can be one of the key elements for better vector control.
\end{abstract}

\section{Introduction}

Mosquitoes infect humans and other vertebrates. Their distribution is to a large extent influenced by climatic conditions and species habits across the globe [1]. Interactions between biotic and abiotic factors can conduct to significant variation in the reproductive landscape of insects [2]. They differ in their preference for the type, size, turbidity, algal cover and stability of the habitat [3]; these factors can lead to determining the density, size and vector competence [3]. Surveying biotic and abiotic factors for various mosquito fauna make it easier to monitor the potential modifications of larval habitats affected by rains, global climate change, and man-made activities [4-6].

In Morocco, many species of Culicidae family have been reported as important vectors of infectious diseases, including the 
presence of the major vectors of malaria (Anopheles labranchiae and Anopheles sergentii (Theobald, 1907)) [7, 8], the Aedes albopictus, responsible for the transmission of dengue, chikungunya, and Zika viruses [9], and Culex pipiens, the potential vector of both West Nile virus [10] and Rift Valley fever virus [11].

Antecedent studies on larval breeding sites have been a valuable source of information regarding the larval biology and ecology of different mosquito species. The search has provided that the factors salinity, $\mathrm{pH}$, and water body permanence determine the occurrence and distribution of larval [12], and water depth and temperature influence larval propagation [13]. Moreover, the human factors like land-use and land-cover changes represent the principal key factor of the mosquito larvae occurrence [14].

Few studies have analyzed the influence of biotic and abiotic factors on the abundance of mosquito species in the Fez region (north central region of Morocco).

The acquisition of knowledge about the larval habitats and estimates of the biotic and abiotic factors associated with the distribution of mosquitos can contribute to an efficient control method.

\section{Materials and Methods}

2.1. Study Area. The study was carried out in the Fez region located in the northern central part of Morocco, characterized by mild and sunny Mediterranean climate and a large human population (1150131 in 2014) (Figure 1).

The study area was limited to four habitat types (dam, swamp, source, and El Oued), categorized into artificial and natural active larval habitats. The selection of habitats was based on their permanent nature and the presence of larvae identified in a preliminary survey.

2.1.1. Lgaâda Dam. The dam has a height of $30 \mathrm{~m}$, with $2.90 \mathrm{Mm}^{3}$ of retention capacity and $10205.21 \mathrm{Mm}^{3}$ of total cumulated capacity. This is an artificial reservoir fed by runoff water which contributes to the supply of drinking water and allows for additional irrigation for crops during dry periods. It is located at $400 \mathrm{~m}$ above mean sea level, $34^{\circ} 01.155^{\prime} \mathrm{N}$ of latitude, and $004^{\circ} 57.213^{\prime} \mathrm{W}$ of longitude.

2.1.2. Awinat Elhajaj. This natural site is a shallow swamp tributary to channels of Lgaâda dam water. It is located at an altitude of $382 \mathrm{~m}, 34^{\circ} 01.226^{\prime} \mathrm{N}$ of latitude, and $004^{\circ} 57.105^{\prime} \mathrm{W}$ of longitude.

2.1.3. Douwar Lhandiya. It is an artificial source located at $410 \mathrm{~m}$ of altitude, $34^{\circ} 02.049^{\prime} \mathrm{N}$ of latitude, and $004^{\circ} 58.512^{\prime} \mathrm{W}$ of longitude. The station choice was made as it is a periurban area, close to the university campus Dhar El Mahraz of Fez, where foreign students with large numbers can be carriers of infectious diseases, typically imported from areas of endemicity.

2.1.4. Jnan EL Alami Oued. It is located downstream of the main water body crossing the city of Fez (Sebou Oued) at an altitude of $242 \mathrm{~m}, 34^{\circ} 04.421 \mathrm{~N}$ of latitude, and $004^{\circ} 57.710^{\prime} \mathrm{W}$ of longitude. It is one of the most polluted rivers in the region and contains pollutants from various sources such as sewage, fertilizers from agricultural fields, and industrial waste.

2.2. Larval Habitat Characterization. The weather and the characteristics of the macrohabitats were recorded, including water use (livestock drink, industry, washing, and irrigation), average depth (measured in three various points of each pool), water flow, slope (zero slope, median slope, and strong slope), color and origin of water (source, river, dam, dam pipeline, and wastewater discharges), proximity to mosquito breeding habitat, surface debris, presence of vegetation, and filamentous algae. In addition, $\mathrm{pH}$, temperature, dissolved oxygen, and total dissolved solids were taken using Consort Multiparameter Analyser C561. The salinity was taken at the same time as electrical conductivity using water quality instrument YSI scientific, and turbidity was recorded by Lovibond ${ }^{\circledR}$ turbidimeter Turbidirect.

2.3. Mosquito Sampling. Larval sampling was carried out every two weeks using a dipping method for a period of one year from November 2015 to November 2016. The sampling was done in about ten ladle dives in several levels. The specimens were preserved in ethanol (70\%).

The typical aquatic habitats sampled are shown in Figure 2. Mosquito larvae collections of each site were labeled with a sampling date, stored in glass flacons, and transferred to the Laboratory of Biotechnology and Preservation of Natural Resources. All mosquito samples were morphologically identified by microscopy at the species level, using the Moroccan key of identification of Culicidae [15] and Mediterranean Africa mosquito identification software [16].

2.4. Statistical Analysis. The statistical analysis has been used to assess the relationships between biotic and abiotic factors and abundance of the most common species especially the species of medical interest. $R$ Software (version 3.4 .3 (2017)) was used for data processing. Data exploration and modeling were used to detect the interactions between variables explained (number of species) and different explanatory variables (biotic and abiotic factors). The "number of each species" is the dependent variable, whereas "presence of vegetation," "water used for washing and water for livestock," "water used for industry," "water used for irrigation," "debris," "color," "weather," "slope," "proximity of industrial establishments," "proximity of construction," and "presence of green filamentous algae" are all nominal independent variables. The quantitative explanatory variables were taken into account according to nine physicochemical parameters such as water temperature $\left({ }^{\circ} \mathrm{C}\right), \mathrm{pH}$, salinity (\%o), dissolved oxygen (PPM), electrical conductivity $(\mu \mathrm{s} / \mathrm{cm})$, flow rate $\mathrm{m}^{3} /$ $\mathrm{s}$, total dissolved solids (g/l), turbidity (NTU), and water depth $(\mathrm{cm})$.

The following models were used:

(1) the logistic regression for low number species like Anopheles maculipennis s.l., Anopheles sergentii 


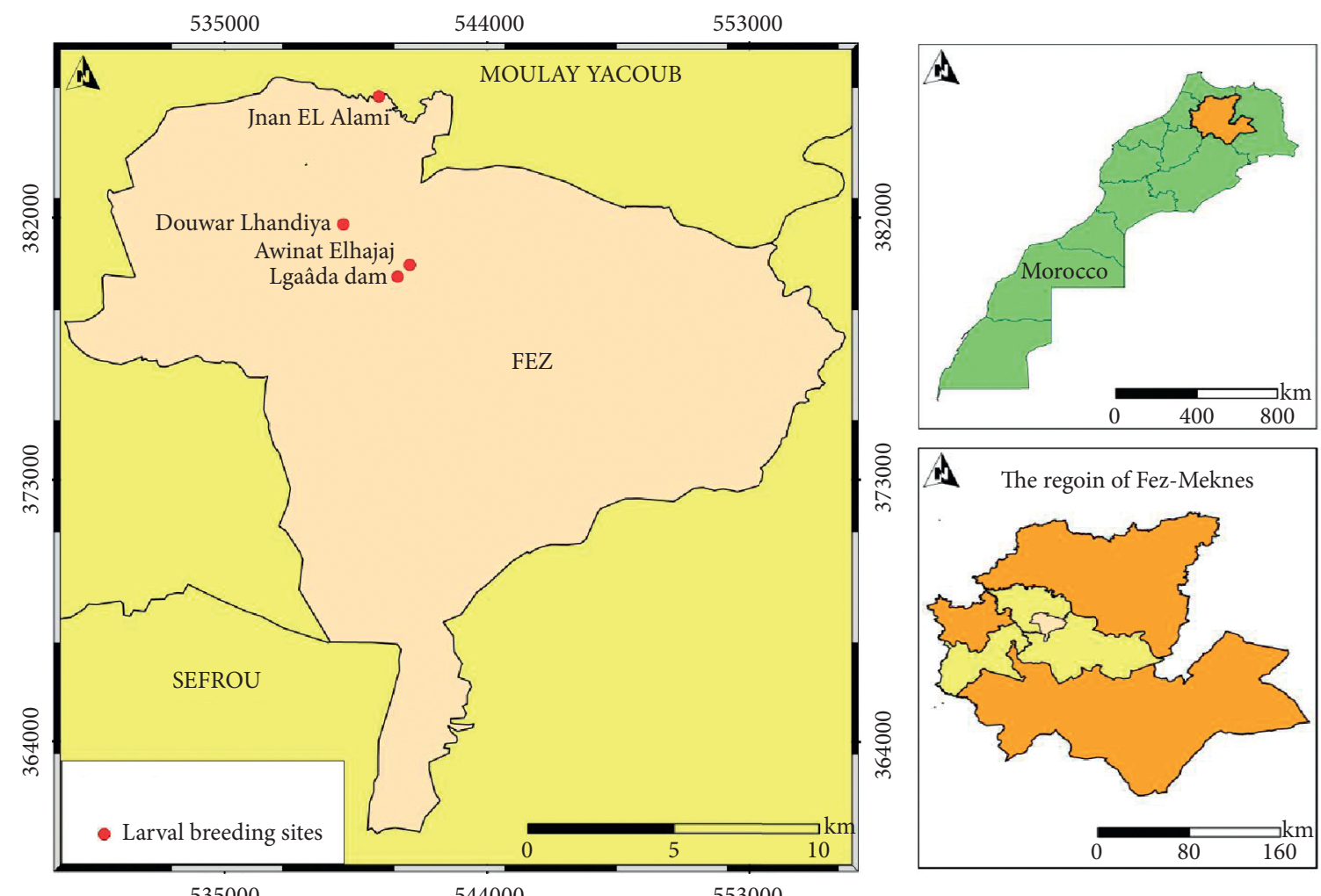

Figure 1: Location of the study area in Fez region (Morocco).
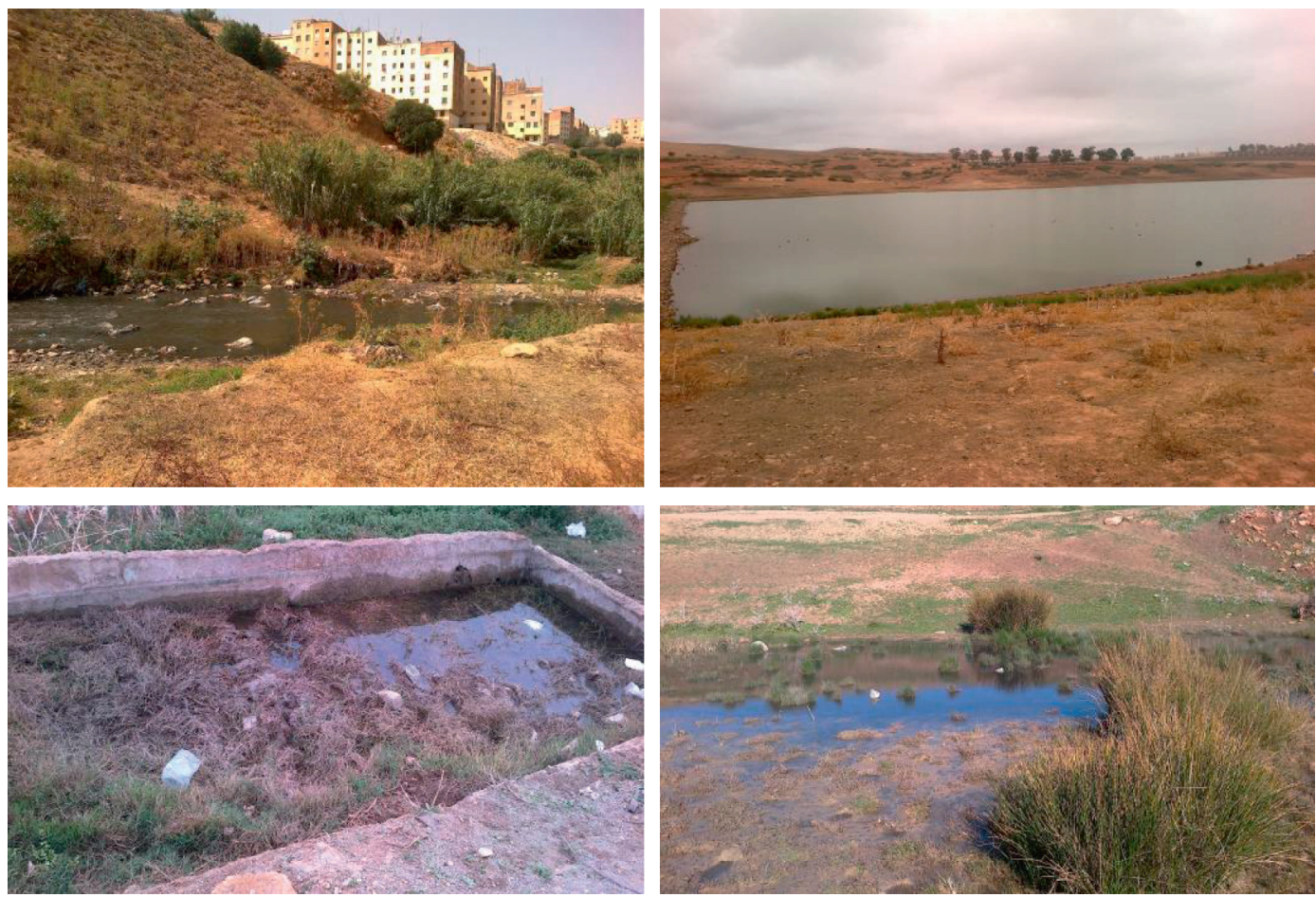

Figure 2: Typical aquatic habitats sampled. 


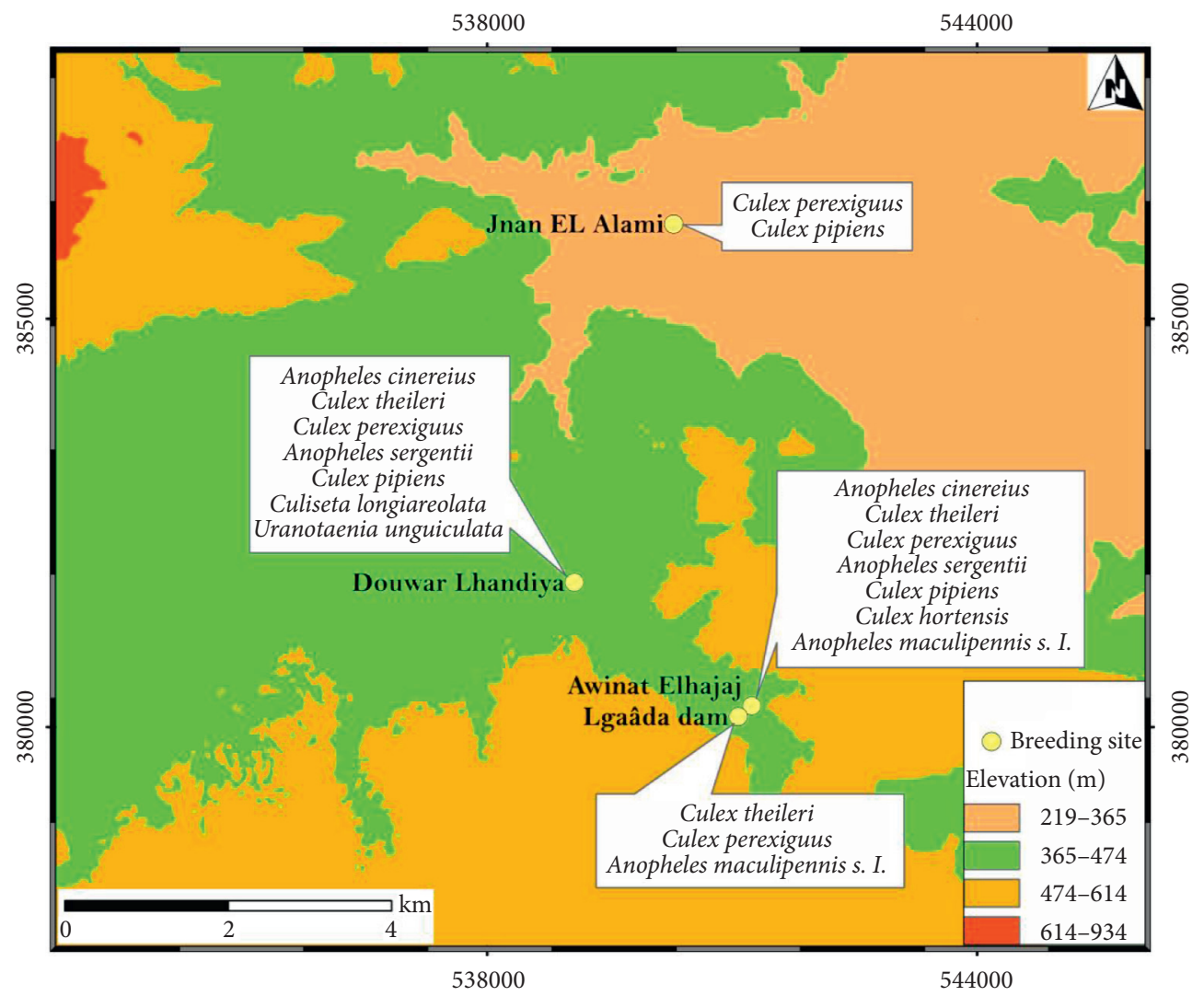

Figure 3: Map showing the distribution of species according to localities and altitudes.

(Theobald, 1907), Culiseta longiareolata (Macquart, 1838) and Uranotaenia unguiculata (Edwards, 1913),

(2) the Poisson regression for more abundant mosquito species, especially Culex theileri (Theobald, 1903), Culex perexiguus (Theobald, 1903), and Culex pipiens (Linnaeus, 1758).

The "vif" function in the car package was used to select independent explanatory variables and testing collinearity, while "glm" and "step" functions are used to select the best models.

\section{Results}

A total of 772 specimens belonging to nine species were collected. Among these species three species of anophelines were identified, including An. maculipennis s.l., An. sergentii (Theobald, 1907) and An. Cinereus. The Culex was more prevalent, wherein Culex pipiens (Linnaeus, 1758) was more common than Culex perexiguus (Theobald, 1903) and Culex theileri (Theobald, 1903), and Culex hortensis was represented by single species. The genera of Culiseta and Uranotaenia were represented by one species (Culiseta longiareolata (Macquart, 1838) and Uranotaenia unguiculata (Edwards, 1913)). The highest species richness (seven species) was observed in Douwar Lhandiya source and Awinat Elhajaj. The most abundant populations were collected, respectively, in Douwar Lhandiya source (448 specimens) and Awinat Elhajaj (217 specimens). The low abundant populations were collected in Lgaâda dam with 448 specimens and Jnan El Alami Oued with 28 specimens. The species common at all four sites was $C x$. perexiguus (Theobald, 1903) (Figure 3).

The results of the logistic regression showed that the species Anopheles maculipennis s.l., Anopheles sergentii (Theobald, 1907), Culiseta longiareolata (Macquart, 1838), and Uranotaenia unguiculata (Edwards, 1913), which are less abundant in the present study, had no statistically significant relationship between their abundance and the biotic and abiotic factors.

The results of Poisson regression analysis (Table 1) showed that the species Cx. perexiguus (Theobald, 1903) has been positively correlated with site proximity to industrial establishments and the presence of debris and green filamentous algae and significantly increased with increasing depth and conductivity but negatively correlated with water flow and dissolved oxygen. Cx. theileri (Theobald, 1903) larval density was observed to negatively correlate with the total dissolved solids and proximity of the sites to building construction and positively correlate with dissolved oxygen, $\mathrm{pH}$, and salinity, The most important observation was that, in relation to the presence of green filamentous algae and vegetation cover, they were statistically positively significant. The result shows negative, highly significant associations between the distribution of Cx. pipiens (Linnaeus, 1758) and the water used for washing and watering livestock, conductivity, and dissolved oxygen and slightly significant associations with $\mathrm{pH}$, total dissolved solids, and water flow. 
TABLE 1: Significant results of the abiotic and biotic factors affecting the distribution of species.

\begin{tabular}{|c|c|c|c|c|c|}
\hline Species & Parameter & Estimate & Std. error & $z$ value & $\operatorname{Pr}(>|z|)$ \\
\hline \multirow{10}{*}{ Culex perexiguus (Theobald, 1903) } & (Intercept) & $1.04 e+00$ & $1.83 e-01$ & 5.69 & $1.2 e-08^{* * *, \neq}$ \\
\hline & WUIr & $-1.68 e+00$ & $4.49 e-01$ & -3.74 & $0.00018^{* * *, *}$ \\
\hline & Debris1 & $2.13 e+00$ & $1.73 e-01$ & 12.30 & $<2 e-16^{* * *, \ddagger}$ \\
\hline & Indu1 & $8.50 e-01$ & $1.83 e-01$ & 4.66 & $3.2 e-06^{* * *, *}$ \\
\hline & Build1 & $-8.26 e-01$ & $1.89 e-01$ & -4.38 & $1.2 e-05^{* * *}$ \\
\hline & GFilAlg1 & $7.06 e-01$ & $2.02 e-01$ & 3.49 & $0.00047^{* * *, \ddagger}$ \\
\hline & DOxy & $-4.57 e-01$ & $4.97 e-02$ & -9.21 & $<2 e-16^{* * *, \ddagger}$ \\
\hline & ECond & $1.99 e-04$ & $7.14 e-05$ & 2.79 & $0.00522^{* *, *}$ \\
\hline & Debris1 & $-2.24 e+01$ & $5.38 e+00$ & -4.17 & $3.0 e-05^{* * *, \ddagger}$ \\
\hline & WDep & $2.26 e-02$ & $3.88 e-03$ & 5.82 & $5.8 e-09^{* * *, \sharp}$ \\
\hline \multirow{8}{*}{ Culex theileri (Theobald, 1903)> } & (Intercept) & -11.9430 & 2.1022 & -5.68 & $1.3 e-08^{* * * \text {, }}$ \\
\hline & PVeg & 1.7545 & 0.3954 & 4.44 & $9.1 e-06^{* * *, \sharp}$ \\
\hline & Build1 & -2.1231 & 0.2939 & -7.22 & 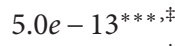 \\
\hline & GFilAlg1 & 1.7961 & 0.3441 & 5.22 & $1.8 e-07^{* * * \text {, }}$ \\
\hline & $\mathrm{pH}$ & 1.2679 & 0.2295 & 5.53 & $3.3 e-08^{* * *, 4}$ \\
\hline & Sal & 1.3591 & 0.2140 & 6.35 & $2.1 e-10^{* * *, \sharp}$ \\
\hline & DOxy & 0.1367 & 0.0644 & 2.12 & $0.03377^{* \text {, }}$ \\
\hline & TDS & -1.0132 & 0.2868 & -3.53 & $0.00041^{* * *, *}$ \\
\hline \multirow{15}{*}{ Culex pipiens (linnaeus, 1758) } & (Intercept) & $1.59 e+00$ & $8.73 e-01$ & 1.83 & $0.06771^{\dagger}$ \\
\hline & WUIn & $-9.94 e-01$ & $2.62 e-01$ & -3.79 & $0.00015^{* * *, *}$ \\
\hline & WUIr & $2.95 e+00$ & $2.63 e-01$ & 11.22 & $<2 e-16^{* * *, \ddagger}$ \\
\hline & Debris1 & $3.86 e-01$ & $1.82 e-01$ & 2.12 & $0.03438^{*, *}$ \\
\hline & GW & $1.26 e+00$ & $4.41 e-01$ & 2.85 & $0.00441^{* *, \ddagger}$ \\
\hline & IW & $2.35 e+00$ & $4.26 e-01$ & 5.51 & $3.7 e-08^{* * *+}$ \\
\hline & YW & $-1.45 e+01$ & $6.81 e+02$ & -0.02 & 0.98304 \\
\hline & ZSlope & $5.57 e-01$ & $2.41 e-01$ & 2.31 & $0.02068^{*, *}$ \\
\hline & $\mathrm{pH}$ & $-1.80 e-01$ & $9.39 e-02$ & -1.92 & $0.05540^{\dagger}$ \\
\hline & Sal & $6.94 e-01$ & $2.20 e-01$ & 3.15 & $0.00164^{* *, \ddagger}$ \\
\hline & DOxy & $-4.49 e-01$ & $4.76 e-02$ & -9.42 & $<2 e-16^{* * *, *}$ \\
\hline & ECond & $-7.10 e-04$ & $1.69 e-04$ & -4.21 & $2.6 e-05^{* * *, *}$ \\
\hline & WF & $-1.64 e+01$ & $2.17 e+00$ & -7.54 & $4.7 e-14^{* * *, \sharp}$ \\
\hline & TDS & $-1.53 e+00$ & $2.30 e-01$ & -6.64 & $3.1 e-11^{* * *, \sharp}$ \\
\hline & WDep & $5.29 e-02$ & $4.80 e-03$ & 11.01 & $<2 e-16^{* * *, \ddagger}$ \\
\hline
\end{tabular}

Std. Error: standard error; $z$ value: estimate/std. error; $\operatorname{Pr}(>|z|)=\operatorname{Pr}(\mathrm{N}(0,1)>\mid z$-value $\mid)$; significance codes: ${ }^{* * *} 0.001,{ }^{* * *} 0.01,{ }^{*} 0.05,{ }^{\dagger} 0.1,{ }^{*} 1$; Buildd: proximity of buildings construction; Indu1: proximity of industrial establishments; GW : green water; IW : incolor water; YW: yellow water; ECond: electrical conductivity; WF: water flow; Debris1: presence of debris; DOxy: dissolved oxygen; GFilAlg1 : presence of green filamentous algae; WUIr: water used for irrigation; pH : potential of hydrogen; WDep : water depth; Sal : salinity; ZSlope: zero slope; TDS : total dissolved solids; WUIn : water used for industry; PVeg: presence of vegetation.

However, the presence of emergent plants, the green and incolor water, and the water used for irrigation were slightly positively associated. In addition, a highly positively and significant relationship was found in terms of zero slope, salinity, and water depth.

The results of the rare observations of An. maculipennis s.l., An. sergentii (Theobald, 1907), Cs. longiareolata (Macquart, 1838), Ur. unguiculata (Edwards, 1913), An. Cinereus (Theobald, 1901), and Cx. hortensis (Ficalbi, 1889) were not explained because we do not have an explicit form of the relationship between variables explained and a set of explanatory variables.

\section{Discussion}

As shown in the statistical analyses, both abiotic and biotic parameters such as component environments and physicochemical parameters strongly affected the abundance of Culicidae, which is already mentioned in literature [3].
Our study showed that the abundance of $C x$. pipiens (Linnaeus, 1758) larvae within the breeding site was not correlated with water $\mathrm{pH}$ which is in agreement with Rydzanicz et al. (2016) [17]. These authors suggest a strong correlation between Cx. pipiens (Linnaeus, 1758) larval abundance and the physical and hydrological characteristics of the aquatic systems, like electrical conductivity. By contrast, this finding was not positively correlated in our data. Other recent studies by Amara Korba et al. (2016) showed that pH, temperature, and dissolved oxygen exhibited comparable values without any relation with larval densities of Cx. pipiens (Linnaeus, 1758) [18], and there were no marked differences in the presence of this species and water flow, distance to the nearest house, artificial or natural larval breeding sites, soluble solid, and vegetation [19]. These results were not in complete agreement with our result. However, other results from another country were in agreement with our study's findings [20]. It was 
confirmed that members of $C x$. pipiens (Linnaeus, 1758) were potentially affected by water flow, water depth, salinity, soluble solid, and vegetation in artificial or natural larval breeding sites [20].

Larvae of Cx. pipiens (Linnaeus, 1758) are able to breed in a great variety of habitats. However, a highly polluted breeding site can inhibit their development [18]. Overall, our findings confirm that polluted water characterized by a yellow color affected the abundance of this species in larval habitat.

Other important factors were strongly associated with the presence of $C x$. perexiguus (Theobald, 1903) larvae and Cx. theileri (Theobald, 1903). Both of them were increasing in the presence of algae [3]. Our results confirmed that species of mosquitoes (Cx. perexiguus (Theobald, 1903), Cx. theileri (Theobald, 1903)) are positively affected by green filamentous algae [3]. In the literature, it is confirmed that mosquito species were generally more present in natural areas than in urban and rural landscapes [21-23]. In our work, the data obtained demonstrate that these two species were less common in the sites near to residential buildings.

Distribution and abundance of Cx. perexiguus (Theobald, 1903) were recognized to show a close relationship with industrial activities and correlate with slow-running water environments, debris, electrical conductivity, and water depth. The last parameter was confirmed to be correlated with this species in another study [24].

Considering our results, water environments with vegetation, dissolved oxygen, $\mathrm{pH}$, salinity, and algae could imply faster larvae development of Cx. theileri (Theobald, 1903). Similar findings have been reported in previous studies conducted in Iran, which reported that the larvae of $C x$. theleri were found with vegetation in natural and permanent habitats [25].

Considering the low number and the rare observations of the larvae (Cs. longiareolata (Macquart, 1838), Ur. unguiculata (Edwards, 1913), Cx. hortensis (Ficalbi, 1889), and Anopheles), the relationship between these species and abiotic and biotic parameters remain unclear. However, the exclusive presence of Cs. longiareolata (Macquart, 1838) in Douwar Lhandiya's source confirms that this species is found only in fresh water pools [26]. All of these species were present in low-water habitats, which confirm that all species are more likely to occur in shallower water [27].

\section{Conclusion}

Our data provide some important findings into the larval habitat. In conclusion, our findings suggest that species of the genus Culex differ in the factors potentially affecting their presence. The preferred habitats of $C x$. perexiguus (Theobald, 1903) were generally characterized by proximity to industrial establishments and the presence of debris and green filamentous algae. The population of this species was increased with increasing depth and high conductivity.

The species of $C x$. theileri (Theobald, 1903) are frequently correlated with dissolved oxygen, $\mathrm{pH}$ and salinity, and they were plentiful in the presence of green filamentous algae and vegetation cover.
The most important factors that greatly affect the abundance of $C x$. pipiens (Linnaeus, 1758) in the region were zero slope, salinity, and water depth.

Overall, our findings provide some results about the influence of biotic and abiotic parameters on the distribution of mosquito species. The results of this study could be useful for the authorities in entomological surveillance to efficiently develop important vector controls.

Further work must be done in order to better characterize the dynamics of these mosquitoes in this region.

\section{Data Availability}

The data used in this study are included within the article.

\section{Conflicts of Interest}

The authors declare that they have no conflicts of interest.

\section{Acknowledgments}

The authors are grateful to the members of the Laboratory of Medical Entomology, National Hygiene Institute, Rabat.

\section{References}

[1] B. Emidi, W. N. Kisinza, B. P. Mmbando et al., "Effect of physicochemical parameters on Anopheles and Culex mosquito larvae abundance in different breeding sites in a rural setting of Muheza, Tanzania," Parasites \& Vectors, vol. 10, p. 304, 2017.

[2] G. Muschet, K. D. L. Umbers, and M. E. Herberstein, "Withinseason variability of fighting behavior in an Australian alpine grasshopper," PLoS One, vol. 12, no. 4, Article ID e0171697, 2017.

[3] A. Animut, T. Gebre-Michael, M. Balkew et al., "Abundance and dynamics of anopheline larvae in a highland malarious area of south-central Ethiopia," Parasites \& Vectors, vol. 5, no. 1, p. 117, 2012.

[4] A. Paksa, M. M. Sedaghat, H. Vatandoost et al., "Biodiversity of mosquitoes (Diptera: Culicidae) with emphasis on potential arbovirus vectors in east Azerbaijan province, northwestern Iran," Journal of Arthropod-Borne Diseases, vol. 13, no. 1, pp. $62-75,2019$.

[5] S. A. Juliano, "Species interactions among larval mosquitoes: context dependence across habitat gradients," Annual Review of Entomology, vol. 54, no. 1, pp. 37-56, 2009.

[6] L. Blaustein and J. M. Chase, "Interactions between mosquito larvae and species that share the same trophic level," Annual Review of Entomology, vol. 52, no. 1, pp. 489-507, 2007.

[7] C. Faraj, E. Adlaoui, S. Ouahabi, M. Rhajaoui, D. Fontenille, and M. Lyagoubi, "Entomological investigations in the region of the last malaria focus in Morocco," Acta Tropica, vol. 109, no. 1, pp. 70-73, 2009.

[8] A. El Ouali Lalami, T. Hindi, A. Azzouzi et al., "Inventaire et répartition saisonnière des Culicidae dans le centre du Maroc," Entomologie Faunistique-Faunistic Entomology, vol. 62, no. 4, pp. 131-138, 2010.

[9] A. Bennouna, T. Balenghien, H. El Rhaffouli et al., "First record of Stegomyia albopicta (= Aedes albopictus) in Morocco: a major threat to public health in North Africa?" Medical and Veterinary Entomology, vol. 31, no. 1, pp. 102106, 2017. 
[10] C. Faraj, M. Elkohli, and M. Lyagoubi, "Cycle gonotrophique de Culex pipiens (diptera: culicidae), vecteur potentiel du virus west Nile," Bull Soc Path Exot, vol. 99, no. 2, pp. 119-121, 2006.

[11] M. Brustolin, S. Talavera, A. Nuñez et al., "Rift Valley fever virus and European mosquitoes: vector competence ofCulex pipiensandStegomyia albopicta (Aedes albopictus)," Medical and Veterinary Entomology, vol. 31, no. 4, pp. 365-372, 2017.

[12] A. El Ouali Lalami, O. El Hilali, M. Benlamlih et al., "Etude entomologique, physicochimique et bactériologique des gites larvaires de localités à risque potentiel pour le paludisme dans la ville de Fès," Bulletin de l'Institut Scientifique, Rabat, section Sciences de la Vie, vol. 32, no. 2, pp. 119-127, 2010.

[13] O. Himmi, Les culicidés (insectes diptères) du maroc: systématique, écologie et études épidémiologiques pilotes, Thése de Doctorat d'Etat, Université Mohamed V, Faculté des Sciences de Rabat, Rabat, Morocco, 2007.

[14] A. Louah, M. Ramdani, Y. Saoud et al., "Biotypologie de la faune culicidienne de la péninsule tingitane," Bulletin Institut Scientifique de Rabat, vol. 19, pp. 93-102, 1995.

[15] O. Himmi, M. Dakki, B. Trari et al., "Les Culicidae du Maroc: clés d'identification, avec données biologiques et écologiques," Travaux de l'Institut Scientifique," Série Zool. Rabat, vol. 44, pp. 1-51, 1995.

[16] J. Brunhes, A. Rhaim, B. Geoffroy et al., "Les moustiques de l'Afrique méditerranéenne. Logiciel d'identification et d'enseignement. IRD \& IPT, CD-Rom collection didactique, Montpellier, France, Éditions IRD, 1999.

[17] K. Rydzanicz, P. Jawień, E. Lonc, and M. Modelska, "Assessment of productivity of Culex spp. larvae (diptera: culicidae) in urban storm water catch basin system in wrocław (SW Poland)," Parasitology Research, vol. 115, no. 4, pp. 1711-1720, 2016.

[18] R. Amara Korba, M. S. Alayat, L. Bouiba et al., "Ecological differentiation of members of the Culex pipiens complex, potential vectors of west nile virus and rift valley fever virus in Algeria," Parasit \&Vectors, vol. 17, pp. 9-455, 2016.

[19] X. Liu and H. Baimaciwang, "Breeding site characteristics and associated factors of Culex pipiens complex in lhasa, tibet," International Journal of Environmental Research and Public Health, vol. 16, no. 8, p. 1407, 2019.

[20] K. P. Paaijmans, W. Takken, A. K. Githeko, and A. F. G. Jacobs, "The effect of water turbidity on the nearsurface water temperature of larval habitats of the malaria mosquito Anopheles gambiae," International Journal of Biometeorology, vol. 52, no. 8, pp. 747-753, 2008.

[21] N. Becker, D. Petric, M. Zgomba et al., Mosquitoes and their control, Vol. 577, Springer-Verlag, , Germany, 2nd edition, 2010.

[22] V. Versteirt, S. Boyer, D. Damiens et al., "Nationwide inventory of mosquito biodiversity (Diptera: Culicidae) in Belgium, Europe," Bulletin of Entomological Research, vol. 103, no. 2, pp. 193-203, 2013.

[23] M. Ferraguti, J. Martínez-de la Puente, D. Roiz et al., "Effects of landscape anthropization on mosquito community composition and abundance," Science Report, vol. 6, p. 29002, 2016.

[24] A. El-naggar, S. Elbanna, and A. Abo-ghalia, "The impact of some environmental factors on the abundance of mosquitoes larvae in certain localities of sharkia governorate in Egypt," Egyptian Academic Journal of Biological Sciences. A, Entomology, vol. 6, no. 2, pp. 49-60, 2013.

[25] A. Sofizadeh, S. H. Moosa-Kazemi, and H. Dehghan, "Larval habitats characteristics of mosquitoes (diptera: culicidae) in north-east of Iran," Journal of Arthropod-Borne Diseases, vol. 11, no. 2, pp. 211-225, 2017.

[26] A. Silberbush, I. Tsurim, Y. Margalith, and L. Blaustein, "Interactive effects of salinity and a predator on mosquito oviposition and larval performance," Oecologia, vol. 175, no. 2, pp. 565-575, 2014.

[27] N. Golding, M. A. Nunn, and B. V. Purse, "Identifying biotic interactions which drive the spatial distribution of a mosquito community," Parasites \& Vectors, vol. 8, p. 367, 2015. 